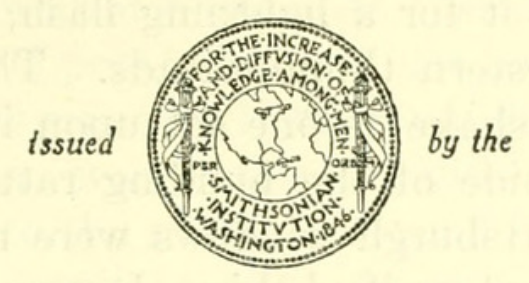

SMITHSONIAN INSTITUTION

U.S. NATIONAL MUSEUM

\begin{tabular}{lll}
\hline Vol. 90 & Washington : 1941 & No. 3111 \\
\hline
\end{tabular}

\title{
THE CHICORA (BUTLER COUNTY, PA.) METEORITE
}

By F. W. Preston, E. P. Henderson, and James R. Randolph

\section{THE CHICORA METEORITE}

\section{By F. W. Preston}

ON June 24, 1938, at 6 p. m., eastern standard time, the weather over western Pennsylvania from the West Virginia border $(1)^{1}$ north to Oil City (2) was fair. Over the central area, the southern part of Butler County, the sky was blue and cloudless $(3)$; north and west were cumulus clouds (4), which in the west approximated thunderheads $(5,6)$ and in the north, a few miles from Butler City, the ceiling was low and apparently somewhat solidly overcast ( 7 ). At Pittsburgh, 2 hours earlier, the sounding balloons from the county airport had been lost to sight a little above 4,000 feet (above sea level) by reason of cloud (8). The winds were light, both at ground level and aloft (8).

The crows had already assembled for their nightly roost in the hemlock woods of the overcast area a few miles north of Kaylor, Pa. (9), but the chickens near Chicora were still scratching in the fields (10), and the geese near Cooperstown were still swimming on a pond (11).

The sun was fairly well up in the sky (12), but it was past business hours: In Butler it was 6 p. m.; in Pittsburgh and the valley towns nearby it was 7 p. m. by daylight saving time. People were gardening, golfing, swimming, playing baseball or tennis, or sitting on their porches listening to the news broadcast over the radio, and some were just sitting. A few seconds before 6 p. m., as the broadcast was changing $(5,6,13)$, a brilliant fireball flashed across the sky from

\footnotetext{
1 The italic numbers in parentheses refer to the list of observers on pp. 401-402.
} 
southwest to northeast; and a few seconds past the hour Butler City and the northern part of Pittsburgh were rocked by a terrific explosion, like a long-drawn thunder roll.

The flash was seen sidelong by some who did not actually witness the meteor; they took it for a lightning flash, though a queer one, and glanced at the western thunderheads. Then the roll came in: the ground seemed to shake as one sat upon it in the garden (14); windows on the east side of the building rattled as if they would never stop (15); at Pittsburgh windows were reported broken (16), though the writer has not verified this. It was realized that this was not thunder. Some thought the boilers in their cellars had exploded; others concluded that a dynamite truck had blown up, as happened a few years earlier just outside the town; then since neither the one nor the other could account for such a massive sound, the rumor spread that the powder magazine at West Winfield had exploded. The rumor was shortly killed by the testimony of eyewitnesses that a great meteor had shot across the sky, in brilliance rivaling the sun (17), which was still high enough in the heavens, and leaving behind it a trail of smoke far whiter than the cumulus clouds beyond it in the north (4).

The sound of the explosion caused some to believe that the meteor broke into two pieces over Bakerstown (18), and there were reports that a part was actually seen to break off and go in another direction; but the most trustworthy evidence is that there was only one smoke trail, and the "explosion" is naturally accounted for by the sudden expansion of the air in the hot trail and not by a shrapnel-like explosion of rending rock.

Toward the end of its trajectory the meteor passed into the overcast area and was observed as a great swirling in the clouds ( $(7)$ or as something ripping the clouds to pieces (19). The country is here sparsely populated, rough, and forested, with deep rocky ravines. Just to the west lies the oil-refining country of Petrolia, and people supposed at first that the oil tanks were blowing up. The main mass of the meteorite has not been located in spite of much searching. The probable point of impact as determined from the trajectory seems to agree well with the testimony of witnesses busy near the spot, and with the absence of testimony from the river valley towns just beyond, but in spite of much searching nothing has been found, for the country is densely covered with forest and other vegetation; and the hillsides are so steep that one must hang onto the trees in places in order to keep upright. What has been found are two small pieces (pl. 54) shed from the main body several miles ahead of the theoretical impact point, and really "discovered" by the chickens. These are the pieces reported upon in detail in the other sections of this paper. 
The belt of country over which the meteor was observed is a long, narrow one. The southernmost point reporting is Nineveh, Pa. (see map, pl. 55), and the northernmost is Titusville. From these points the meteor was seen, but not heard. At Washington, Pa., the meteor was observed by several people but was not heard, although a powerful smell of sulphur was reported 15 or 20 minutes after the apparition.

Most of the observers were somewhat directly on the track of the meteor, i. e., under it to the south or beyond it at the north end, and only a few were sufficiently to one side of it to provide good intersecting shots upon the trajectory. However, a couple of good observations were obtained from eastern Ohio, and there were some, a little less accurate, from points east of the trajectory.

The time of day and year and the climatic conditions were favorable for the phenomenon to be observed by many witnesses. A considerable number of them have been interviewed in order to get the best possible estimate of the trajectory, in hope of locating more pieces of the meteor, and also to get the most accurate description possible of the phenomenon, for it will surely be rare for a great meteor to fall so obligingly in full view of thousands of witnesses spread over so wide an expanse of fairly well populated country.

From their reports, the trajectory has been reconstructed (let us hope without too great inaccuracy) as described later, and illustrated (map, pl. 55). Some of the observers add interesting details.

The meteor passed like a flash, leaving behind it a very narrow trail of smoke like a pencil mark on the blue sky (17); almost instantly (the observer estimated $1 \frac{1}{2}$ seconds) this expanded sideways until it was about wide enough to block out the moon (the moon was not visible then). Another observer reports a spiraling (11) of the smoke. Two independent observers report the smoke as drifting slightly to the northwest. In these latitudes, the upper air currents are somewhat persistently from the northwest. The "winds-aloft" report from the United States Weather Office in Pittsburgh fails to indicate any such drift, and either observers are in error or some local disturbance affected the smoke, or the Weather Bureau observations are incomplete. At noon and at 4 p. m. on June 24 the Bureau's observations were obstructed by cloud at 4,000 feet.

After the fireball passed Cooperstown, and before the sound arrived, a large flock of geese, swimming on a pond, all left the water, climbed onto the land, flapped their wings, and honked furiously $(4,11,20)$.

At Chicora, a farmer (10) was sitting on his porch when there came a sound like an approaching airplane, and a great gust of wind. The chickens in a nearby paddock were wildly excited and objected to something in their midst, but a search failed to disclose what it was all about. Next day, hearing of the meteorite, the farmer searched 
again and discovered two pieces of it, the larger about half the size of a man's clenched fist, the smaller, half that size. They were stony meteorites, the outer skin melted, resolidified, and slightly cracked, and they were buried 2 or 3 inches in the grass roots. The impression fitted the stone well, and the stone appeared to have fallen vertically. The farmer reports no flash of light or roar of thunder, but only a noise like an airplane and a great gust of wind. In a neighboring field a cow was discovered to have its hide torn downward as if struck a glancing blow by a falling stone, and it was necessary to have a veterinarian tend to it.

Other observers in the neighborhood of Chicora and just north of it heard no thunder roll, but some report hissing sounds. One observer, however, an 8-year-old child (21), spoke of the meteor as "the wheels of the thunder wagon."

Twenty miles farther on, at Oil City, a group was playing tennis. A foreigner yelled "Starfire!" and several observers saw the fire approaching, but falling short of them behind the housetops. The compass observations of their reports place the object rather remarkably west of most of the other "shots" and extraordinarily high in the sky. At present neither of these facts can be accounted for (22).

At Reno, a few miles west of Oil City, a jeweler (23) observed the fireball approach. It fell, he said, just across the Allegheny River in a deeply wooded ravine. It left a trail of smoke, which slowly drifted away. Nothing was heard, but the azimuth of the "shot" traces a line to Chicora. At Franklin also (24) the thing was observed in the direction of Chicora. Still farther north, at Titusville, a business man (25) in his office happened to notice it, and his observations place it over northeastern Butler County.

In the west, on the East Palestine golf links across the Ohio border, golfers $(26,27)$ saw the streak across the eastern sky. On the lower Allegheny, around Oakmont and New Kensington, observers (28, 29, 30) saw it in the north. But so far practically no one has been found who saw it against the western sky; east of the trajectory we get no reports. This is unfortunate for the accurate locating of the trajectory. The explanation probably is that the sun was low in the west ( $18^{\circ}$ above the horizon), and if the sky was clear in the west the meteor would not be seen against the sun. And where the thunderheads, black and threatening $(5,6)$, obstructed the western view, the cloud of smoke would not be visible because the sun would not be shining on it, while the flash would be taken for lightning in the west.

The smoke trail, of vaporized rock, lasted in a clear form for at least half a minute. Yet observers differ greatly in their accounts of it. One man (3/4) thought it was airplane skywriting and spent his time looking for the airplane in front of the smoke. Another (32) did 

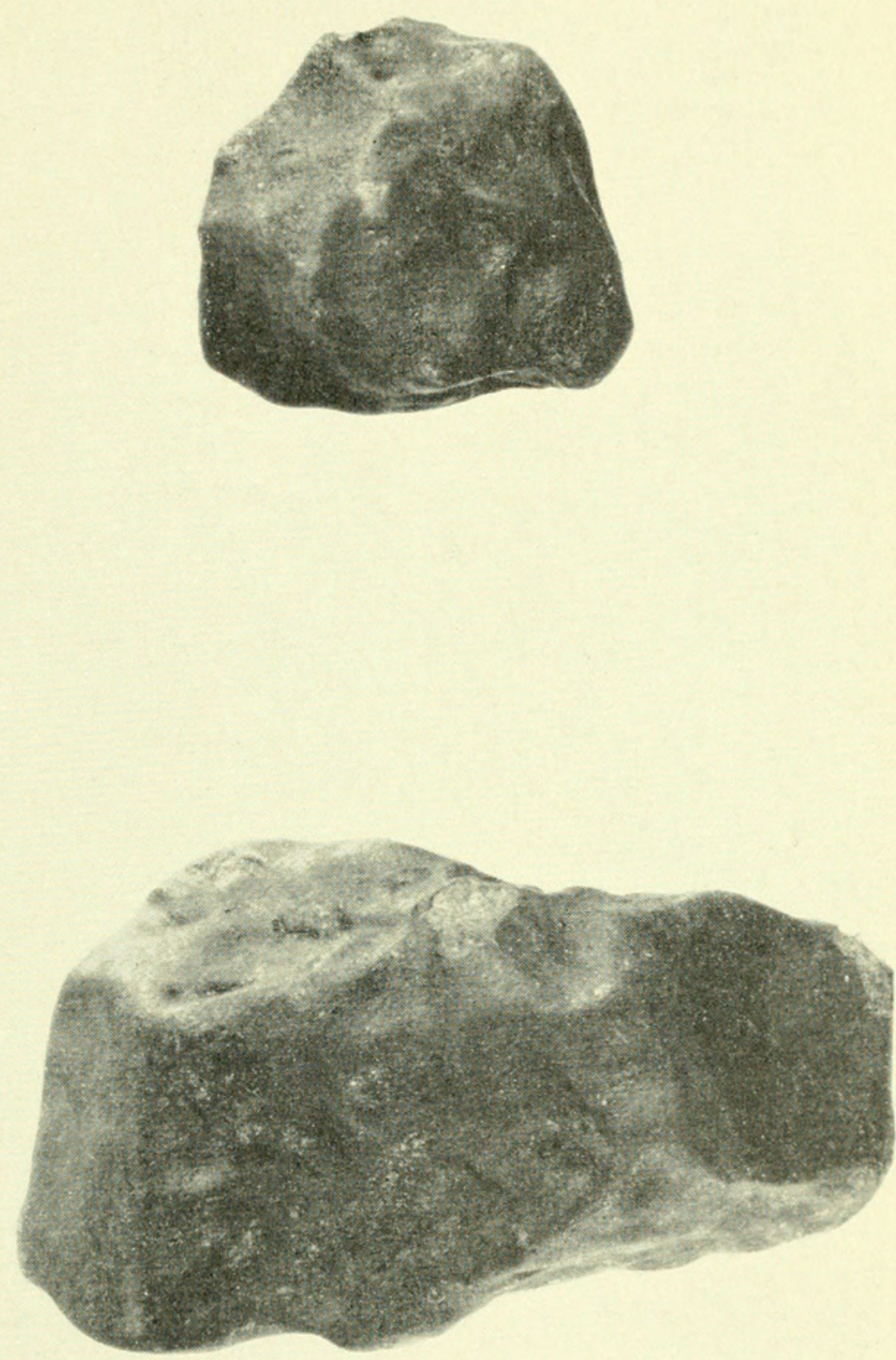

The two individuals of the Chicora fall. The larger weighs 242 grams, the smaller 61 grams. 


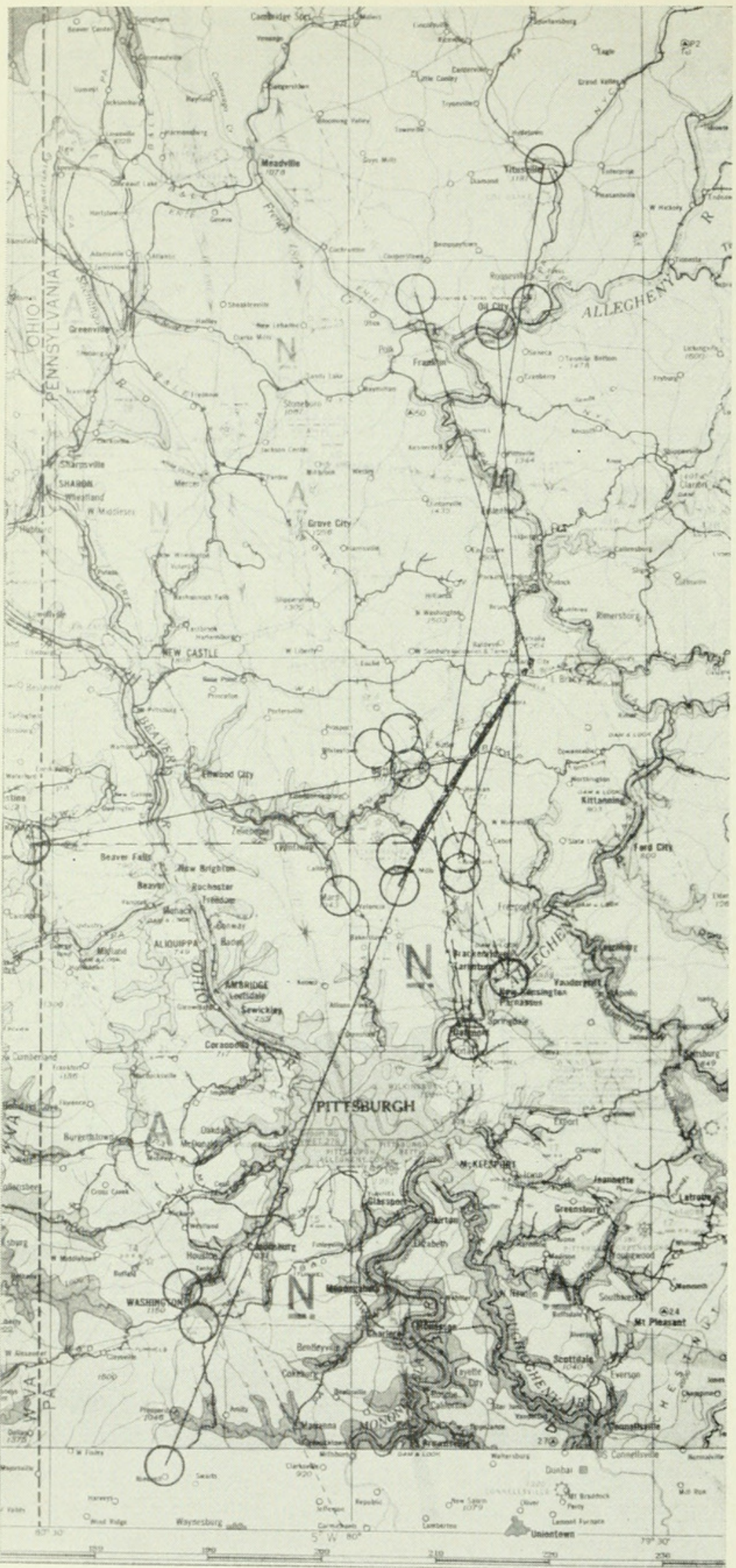

(See opposite page for explanation.) 


\section{Plate 55}

Terrain covered by witnesses. Circles represent locations of some of the witnesses; thin black lines represent their observations onto the trajectory; broken black lines represent estimates of the top of the visible smoke trail. Thick black line represents estimated path of meteor as seen in plan from top of visible trail to its end. Broken continuation of line to northeast represents reports of "swirling clouds," “clouds torn apart," “crows deserting roost," etc., up to the point where in the absence of atmosphere it is estimated that the meteor would have hit and where parts of it may be.

Observations from the north are nearly all lofted into the air and are too high in elevation as compared with those from the south, east, and west.

Scale: $1 / 2$ inch $=10$ miles. 


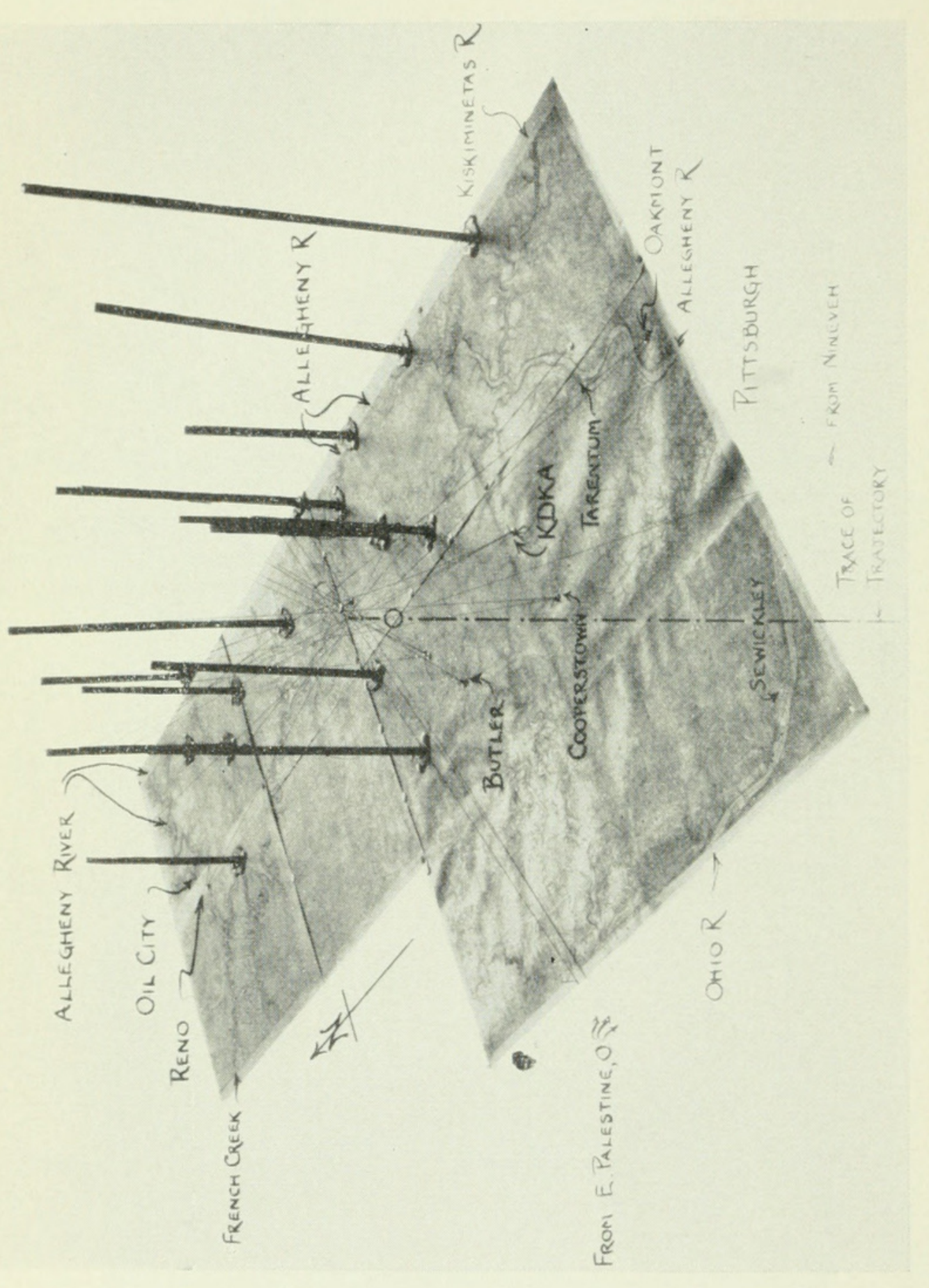

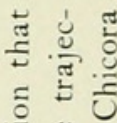

范

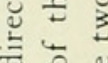

ब

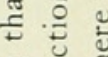

我.

음

단

3

3 요

궁

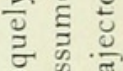

政

요

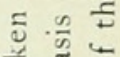

ฮู

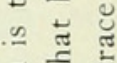

돈

ธะ

कृ ฮ

을

के

E

. 敞

के के

¿ 8 บั

ह

ช

5

$\Xi 气$.

है ธี छี

bo.

का $\frac{1}{\pi}$ क

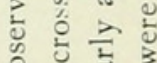

० บ

s.

क त

क है है

है 
not notice it till it was all there, and since it reached the ground in the north, but not in the south, he concluded it was some sort of rocket that started in the north and traveled southwest into the sky. One witness (11) reports that the trail had a spiral track in it, and others $(7,19)$ describe it as "twisting clouds" or a "swirling streak in the clouds." One (5) reports that the track was confined to a narrow strip near the zenith and did not go anywhere near the horizon, while others $(6,13)$ in his immediate neighborhood traced it to the horizon. However, the former is not alone, for from other points an airplane pilot (34) reports the trail as stopping short of the northern horizon as seen from the Butler Airport, while an observer near Chicora insists that the trail broke up and did not descend to the ground. One observer (31) insists that the trail crossed the sky completely but was intermittent. Observers near Mars, Pa. (18), thought the meteor broke up near them, but so did people in Pittsburgh. This variance is probably due to the effect of the roar of the "explosion," which they were psychologically unable to dissociate from the notion that the thing must have blown to fragments. The roar comes from the sudden expansion of the very much heated air and boiling stone, not from an explosion of solid matter.

The meteor, as shown by its track, had passed around the sun and was now receding from it, when it overtook the earth. The difference in the two planetary velocities was presumably a few miles a second, from astronomical considerations. This is roughly 10 times the velocity of sound in air. The meteor was not spherical, but flat or irregular, and rotating rapidly, if we can judge by the spiraling of the trail.

The resistance of the air slowed it down and raised its surface temperature to brilliant incandescence "like the sun." The limit is set by the melting and boiling of the stone, which would probably be in the neighborhood of $2,000^{\circ} \mathrm{C}$. This likewise sets a limit to the temperature attained by the surrounding air.

The pitch of the sound near Butler was a deep roar like thunder; at Chicora, a sound like an airplane; at Kaylor, a hiss. A proper interpretation of the sound might yield interesting results. (See section by Randolph.)

The meteor passed completely unobserved at the Pittsburgh County Airport. It was, however, observed at the Butler (Alameda) Airport by several persons. The Pittsburgh-Butler Airport was not checked. A pilot (34) in a small open plane was flying over Butler when the meteor went by, but he had his back toward it and saw nothing till he landed, when the smoke was still visible in the sky. This was probably a minute or two later, at the earliest. Such a result is to be expected, with the calm air conditions reported at lower levels. 
The pilot of a Pittsburgh-Buffalo plane, which should have taken off at 6 p. m. sharp from Pittsburgh, reported no observations of the meteor, though if visible at all it should have been conspicuous from the copilot's seat, particularly if the trail endured for a couple of minutes.

Pittsburgh proper, however, turned in several reports of the meteor, though the Pittsburgh Airport, 6 or 8 miles to the south, missed it completely. These Pittsburgh reports, some of which are excellent, did not reach me till Feburary 1, 1939, half a year after the event. They had been sent to Canada or to Philadelphia and were finally forwarded to me by Dr. Charles P. Olivier, of the Flower Astronomical Observatory and director of the American Meteor Society.
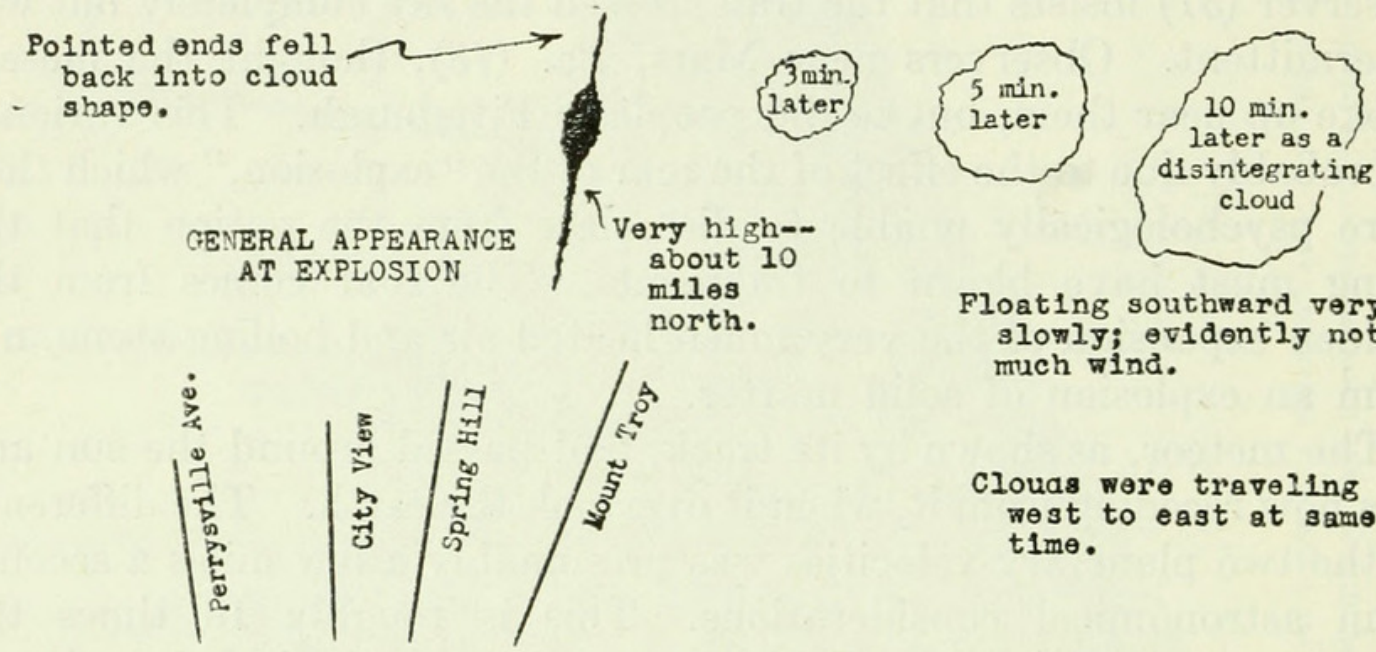

Floating southward very slowly; evidontly not much wind.

Clouas were traveling west to east at same time.

Figure 19.- Sketch of clouds and explosion as noted from "north side" Pittsburgh.

An observer (36) on the "north side" of the city (i. e., north of the Allegheny River) reports on June 26: "Myself and young son witnessed this phenomena. We usually watch for an airplane that flies over each night shortly after 7 o'clock (D. S. T.). Scanning the skies we saw this flash, then a puff of smoke, thin-pointed skyward, much thicker in the center with a jagged-edge appearance, and smooth thin-pointed earthward; called wife from house who witnessed and verified belief in smoke theory instead of cloud. About 1 or $1 \frac{1}{2}$ minutes later heard explosion much louder and higher than fireworks bomb, and watched smoke assume appearance of a cloud drifting slowly southward and disintegrating over a vast space; smoke was a vivid white." Figure 19 is a copy of his sketch. The time interval (1-1 1/2 minutes) is probably somewhat underestimated. The sketch shows the smoke moving eastward, but reports it moving southward. It also mentions clouds.

From Oakmont, which is about 10 miles from downtown Pittsburgh in a direction somewhat north of east, the wife of a science teacher 
reports a time delay of 1 minute. The explosion shook houses, and people ran into the street to see where the explosion was. The time is reported as 7:30 p. m. (E. S. T. no doubt, but in any case half an hour in error).

Leo J. Scanlon, secretary of the Valley View Observatory, Pittsburgh, obtained information from John Dengler, of north side Pittsburgh: "Time of passage (about) 7:10 p. m., D. S. T., June 24, 1938. Direction: Headed $30^{\circ}$ east of north (from compass bearing by Scanlon). Altitude about $40^{\circ}$ when first seen, extremely brilliant head (about as bright as 200 -watt lamp at 50 feet), leaving a bright train of white smoke, which persisted for at least a minute and a half. (Others reported it as being visible for about 20 minutes.) Noise: Sharp and loud report, followed by a rumble, which began at about the same pitch as the explosion, gradually growing fainter. Noise heard about 2 to $2 \frac{1}{2}$ minutes after passage of fireball, which was moving at a speed of about $45^{\circ}$ of are in 3 seconds (estimated by Leo $\mathrm{J}$. Scanlon from rehearsal of observer)." The time interval appears to be getting reasonably close.

An observer at the North Park, some distance out of Pittsburgh, reports the smoke trail as vertical and in the northeast. This seems correct, for according to our evidence the meteor passed almost over the Park before reaching the atmosphere, and was headed more or less northeast.

Prof. Charles Williamson and W. H. Bessey, of the physics department of Carnegie Institute of Technology, observed the phenomenon from the parking lot northwest of the engineering hall on the campus. Writing to Dr. Jordan, of Allegheny Observatory, on June 27, Williamson says: "At $6: 58$, E. D. S. T., the trail was seen by W. H. Bessey of this department and myself, from the parking lot northwest of our engineering hall. We can fix the time with some precision because I looked at my watch and checked it by an electric clock 3 minutes later. Mr. Bessey, who witnessed the flash, says it was of astonishing brilliance. It appeared in an unclouded part of the sky.

"Today, I took the bearings of some structures belonging to the United States Bureau of Mines above which the trail appeared. Its direction was approximately N. $30^{\circ}$ E. The trail was almost exactly vertical as seen in projection; it extended from about $40^{\circ}$ to about $25^{\circ}$ above the horizon, widening from the top to, say, $30^{\circ}$ above the horizon, and tapering below. This surprised me and made me infer wrongly that it might be a tracer bullet from some airplane. Atits widest point the trail had a breadth of perhaps 30 seconds of are. It persisted for upwards of 30 seconds and showed no noticeable drift. "We heard the burst at approximately 7:05, but unfortunately I did not look at my watch." 
These observations are among the most accurate we have, except that the trajectory should have sloped somewhat, and not have been vertical. For the rest it agrees with our general conclusions. Note Williamson's agreement with Heyl, as to a wide part on the trail. Thirty seconds of arc is the width of the moon's disk and was about 25 miles from the observer. This implies a trail about 2,000 feet wide at this point.

R. V. Bergvall, assistant to manager of engineering, Westinghouse Electric \& Manufacturing Co., writing to the Royal Astronomical Society of Canada, on June 27, says: "I observed a meteor on June 24, 1938, at about 6:00 p. m., E. S. T., from 24 Hillerest Road, Forest Hills, near Wilkinsburg, Pa. Thinking that a reasonably accurate reference might be of value, I spotted the center of the smoke in line with two landmarks that happened to be available and later measured the angle, using the location of the North Star as a reference. The measurements were made with a protractor. The central line of the smoke appeared $7^{\circ}$ east of north and was exactly $40^{\circ}$ up from the horizontal. The smoke subtended about a $15^{\circ}$ angle, as closely as I could judge from memory after having obtained the protractor. The smoke trail tilted about $5^{\circ}$ from vertical, the downward point being toward the east. The smoke drifted slowly toward the west. My wife observed the actual flash and reports that it did not reach ground. I believe that this observation is correct because of the limited length of the smoke line. The sound of the explosion was heard in about 2 minutes, but this time observation is not at all accurate."

Bergvall notes the slope of the track and places the meteor fairly accurately in the Chicora region. Mrs. Bergvall's report that the flash did not reach ground also is true, and the timing is not so far out. There is the mystery of the smoke drifting toward the west, also reported from Cooperstown and Butler, while Heyl reports it drifting south, and the clouds drifting east. Possibly the apparent motion is due, in part at least, to the settling of the smoke.

William A. Knoch writes: "I was sitting on the porch of my house, 7220 Hermitage Street in Homewood, with my sun glasses on just looking up at the sky, when I was amazed to see a long streak of fire going across the sky toward the earth at an angle. After going so far it stopped like something bursting. It continued with another streak and then ceased. After this bursting there was a small quantity of smoke which continued to hang in the sky. If you had not known it was caused by this meteor, you would have thought it was a small cloud. I thought at first it was a skyrocket that might have been shot from an airliner, but there was none around. I remained in this position watching the smoke. About 5 minutes later the whole window behind me shook until I thought the glass would break. I never 


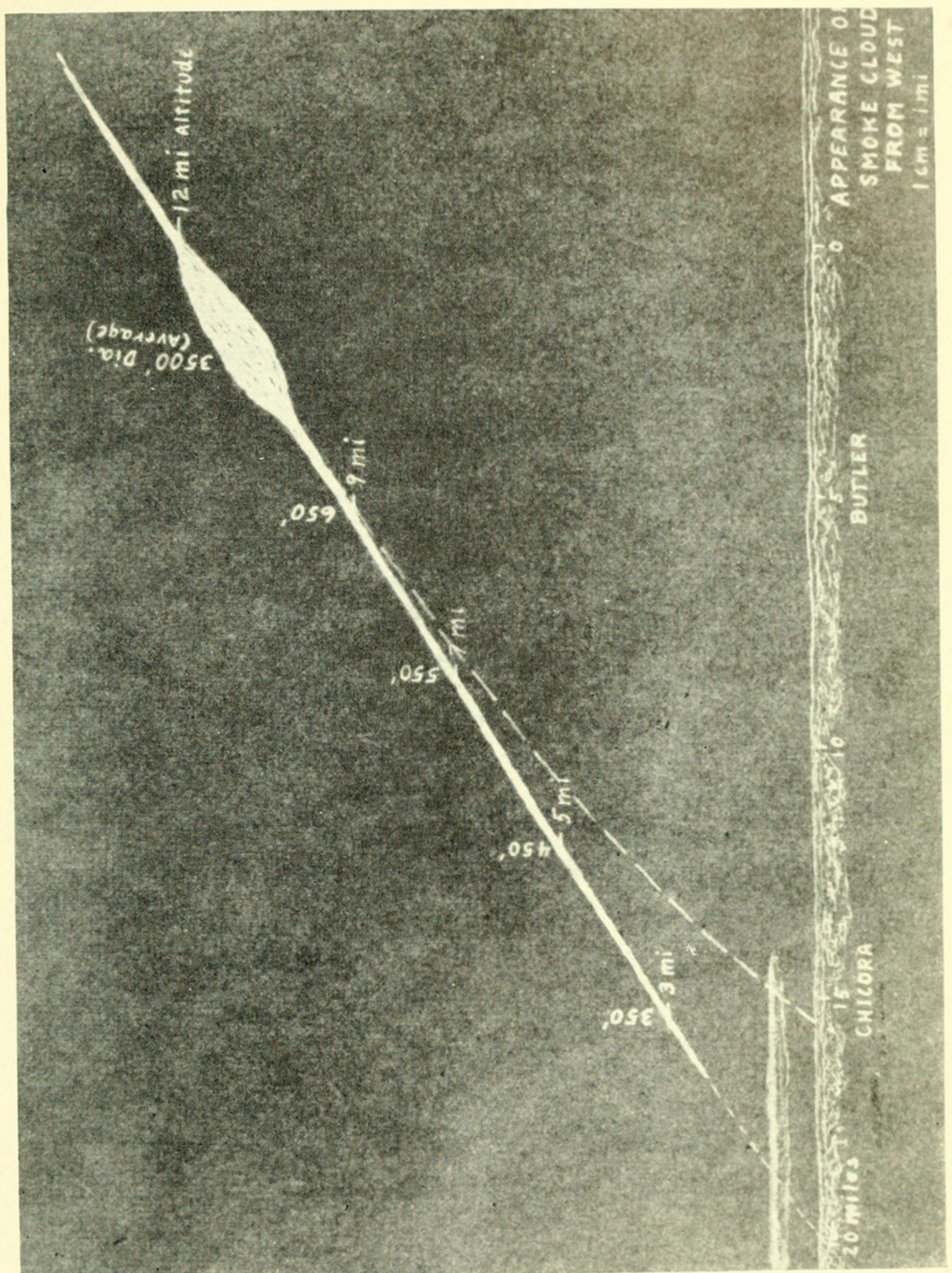




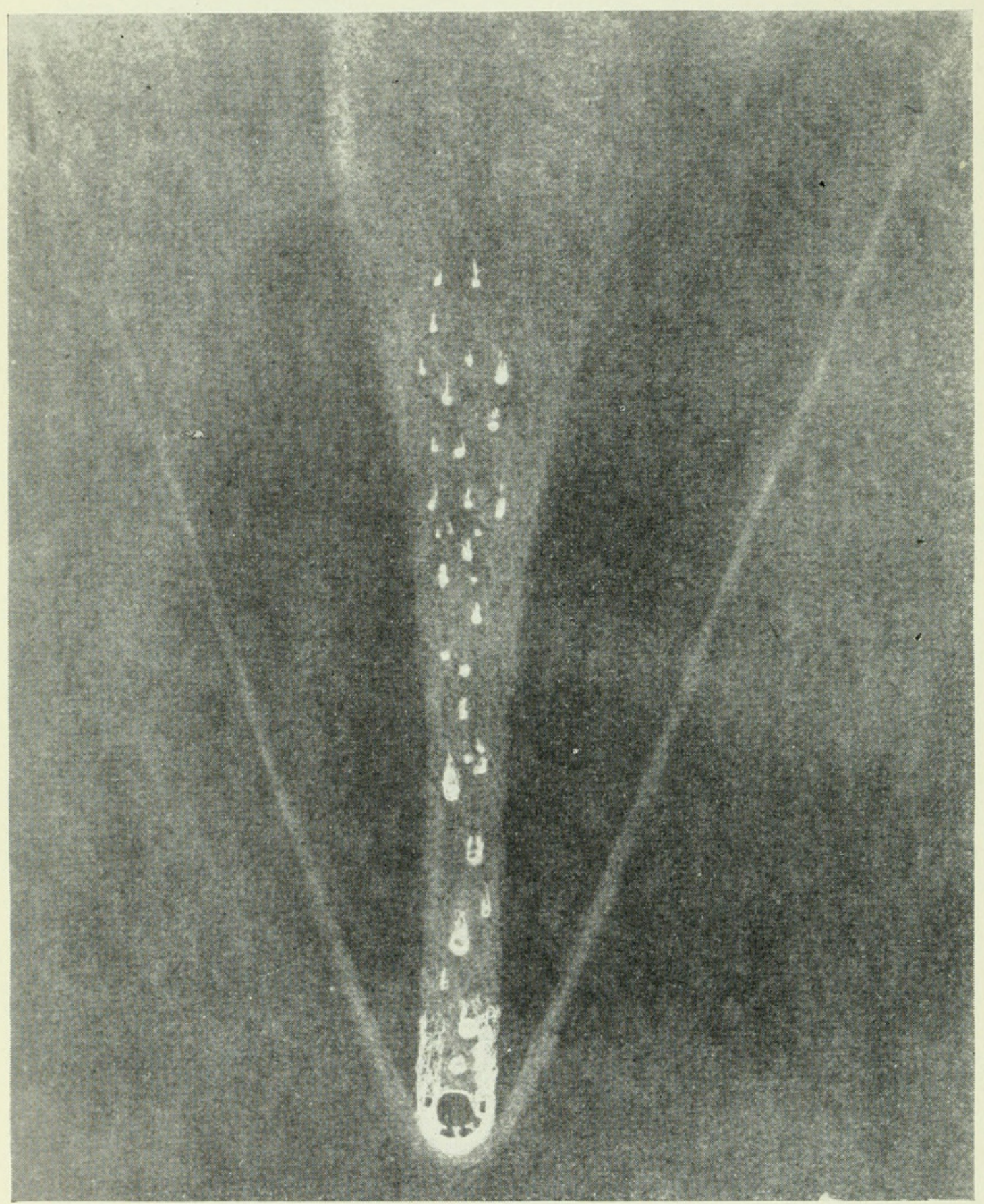

Drawing illustrating the absorption of kinetic energy of the meteorite by the air. 
connected the two as coming from this source. I thought there had been an explosion somewhere, and as I had my police radio on I Jistened for a fire call. About 5 minutes later there was a report of a fire on Melwood Street. Once before I had heard an explosion in a garage on Melwood Street, which had caused a fire alarm to be turned in. I thought this was a similar case and did not know differently until I read your account in the paper. Some of the people in the neighborhood thought the Italians on Larimer Avenue were having a celebration. This meteor was directly north of my home, seemingly up above Aspinwall."

This confirms the observation from Saxonburg that the smoke trail gave the impression of being intermittent. It agrees well with the other observations.

One other report comes from Oil City, beyond the north end of the track. An observer at Oil City golf course saw both flash and trail in the southwest, more west than south, but heard no sound. The smoke trail persisted for about 15 minutes. The observer thought the meteor might have fallen as far off as West Virginia. This observation agrees with other Oil City observations in placing the meteor much too far west. There was apparently something queer about the atmosphere near Oil City that day.

See plate 57 (drawing of meteor track) and section hereinafter by Randolph. The thin upper cloud in this drawing would be missed by Butler observers, and its top might be missed in Pittsburgh, but to Oil City observers this would be the most conspicuous part of the track, the lower parts being hidden by terrain features. Oil City observations give the best indications of the height at which the meteor first became visible.

The time of the meteor's passing is fixed with considerable precision at Station KDKA, where the broadcast was just signing off. The streak was first noticed at 7 seconds before 6 p. m., E. S. T., and the roar of the "explosion" came in at 24 seconds past 6 p. m. The fireball itself was not observed by these observers $(5,6)$. One observer (13) also reports the radio broadcast program as in process of changing when the meteor passed.

A large number of observers who believed they could indicate the track of the meteor in the skies, or its point of disappearance below the horizon, have been interviewed, and transit observations taken of azimuth and altitude. The azimuth is obtained from magnetic north but is corrected to true north before entry in the table. Some of these observations are much more accurate than others, owing in some cases to more careful observers but often to topographical features that preclude serious errors, either as to the position of the observer or as to the features on the horizon. Accordingly, we have tried to label the 
observations as of $\mathrm{A}, \mathrm{B}, \mathrm{C}$, and $\mathrm{D}$ grade, in respect of either azimuth or altitude. An A grade means that we think the probable error lies within $\pm 1^{\circ} ; \mathrm{B}$, within $\pm 3^{\circ} ; \mathrm{C}$, within $\pm 10^{\circ} ; \mathrm{D}$ means we think the observations qualitative only, or in serious error. In attempting to rate the observations this way, we may ourselves be in error or prejudiced.

TABLE 1.-Transit observations of the track of the Chicora (Pa.) meteorite

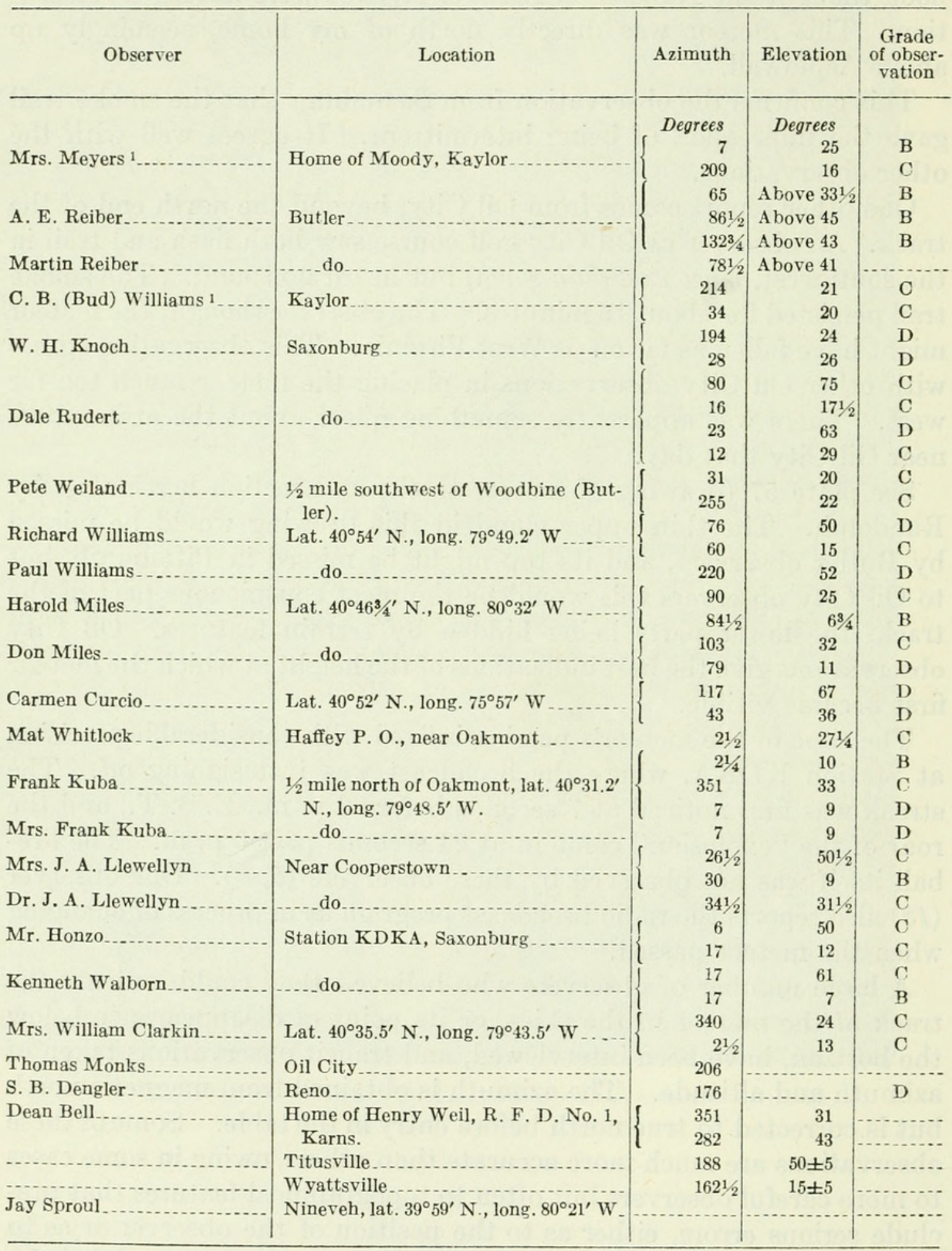

1 Did not see actual meteor, but swirling clouds. 
Having obtained these bearings of the smoke trail, reconstructed from memory after a lapse of some weeks, we have plotted them on the United States topographical survey, 1/62,500 scale (roughly 1 inch to the mile), by means of strings stretched in the air above the maps, and in this way have tried to locate the correct trajectory (pl. 56). It is to be assumed that the trajectory will be nearly a straight line, and quite straight as seen in plain view.

The first sound of the "explosion" reaches a given spot on the ground, from the nearest point of the trajectory, or very nearly, since the meteor is traveling many times as fast as the velocity of sound. The succeeding sustained roar is due to the expansion of the air in both earlier and later parts of the trajectory. If the time interval were known with precision in any case, the length of the radius vector to the nearest point on the trajectory would be known with fair accuracy.

Around Chicora the time delay is reported as very slight. At Butler it was reported as about 8 seconds after the track was seen to expand $(17)$, but that is probably an underestimation. At Station KDKA (Saxonburg), where the radio operators are extremely "timeconscious" and know exactly at what stage the signing-off of the program stood, the delay was at least 31 seconds. At Cooperstown one observer (11) saw the flash, and then the trail, and immediately called wildly for another (35) to come and look. The latter young lady was in the locker room, getting dressed for swimming, and ran out as soon as she could. She arrived ahead of the thunder peal by at least several seconds. I had her reenact the scene from the same degree of dishabille in the locker room, and she was out in 24 seconds. This sets a minimum limit, but the general belief of the four persons present was that the explosion was delayed a good many seconds beyond the 24 . This places the trajectory at least 5 or 6 miles away. Beyond agreeing with the KDKA reports, these observations are of little help.

\section{PROBABLE TRAJECTORY}

Plate 56 shows a map of the central part of the terrain in which the phenomenon was observed, and the thin black lines are black threads representing observations, with a "transit" (theodolite) from various places on the ground, of the line of sight to some point on the smoke trail. Each thread arises from a thumbtack representing the position of the eyewitness, who was then asked to set the instrument on the highest point of the smoke trail and on the lowest point, as nearly as he could remember.

If every observer had been accurate, or if each could have had a transit all set up and ready to take the observations when the meteorite 
appeared, then all the "shots" would cross on a straight line sloping down from southwest to northeast. Since all observers, under the actual circumstances, are in error by greater or less amounts, the problem is to get as good an intersection as possible from a great number of "shots," none of which are exact. This was done by first rejecting observations that did not fit at all, and then sighting among the remaining threads till they appeared to cluster into a small bunch. The photograph (pl. 56) is taken down this line of sight, which we assume to be the approximate trajectory. This trajectory descends at an angle of $31^{\circ}$ to the horizontal and bears $33^{\circ}$ east of true north. The horizontal trace of this trajectory is shown in the figure; the trajectory itself, since we are looking down on it, is a single spot marked by the north end of the trace. The small circle, on the trajectory trace, represents the place near Chicora where the fragments were recovered.

It will be observed that, with one exception, the threads do cluster fairly well when seen from this position. However, moderate shifting of the point of view and moderate changes of azimuth and angle of descent give intersections nearly as good, so there is some substantial uncertainty on all these points.

\section{POINT OF IMPACT}

According to the map, the meteor, unless entirely fragmented, should have passed a good many miles beyond the place where the two fragments were found, and should have landed within a short distance of the Allegheny River, in wild wooded country with precipitous ravines. A canvass of every farmhouse in this district indicates that very likely it did reach this region.

It appears that in this district the sky was overcast, presumably with clouds not higher than 5,000 feet above sea level or about 3,500 feet above the ground. A party of young baseball players ( 7 ) report hearing a hissing sound and, on looking up, noticing a great swishing in the clouds. Not far away two women report seeing the clouds ripped to pieces.

In a precipitous valley clothed largely with hemlock trees a flock of crows is accustomed to roost, and they had already assembled that evening by 6 o'clock. One woman noticed that on the arrival of the meteor the crows all were protesting and flew away, and another farmer's wife observed where the birds spent the night some distance away. They returned to their usual haunt next evening and have been there since.

Beyond this point, in the main river valley, there are no reports of the meteor, and there is every reason to believe it did not cross the Allegheny River. 
On the evidence of the crows, and the apparent trajectory, $\mathrm{Mr}$. McCormick has spent many hours searching the ravine in question. He reports that it is scarcely possible to stand without hanging on to the trees, and that it takes one man a day to search an acre or two. His searches have so far proved fruitless. Mr. Aderhold chartered a small plane and flew over the woods in this district looking for evidence of damaged trees, but he was also unsuccessful. Obviously a meteor or collection of fragments weighing many hundreds of pounds and perhaps tons could fall in such a place and except by accident never be discovered.

The evidence, however, of the two fragments actually recovered is that fragments falling nearly vertically were shed miles ahead of the theoretical impact point. Since we cannot assume that two small fragments of stone, weighing a few ounces each and traveling with a normal terminal velocity, could have created a sound like an airplane or a great rush of wind, it is clear the main meteor lies northeast of the recovered fragments. But since there are some miles of territory between Garing's farm and the theoretical impact point, and the country is mostly under dense vegetation, the prospects of recovery are not bright.

Theoretical impact point is about latitude $41^{\circ} 1^{\prime} \mathrm{N}$., longitude $79^{\circ} 40^{\prime} \mathrm{W}$.

Recovered fragments are from approximately latitude $40^{\circ} 56^{\prime} \mathrm{N}$. longitude $79^{\circ} 44^{\prime} \mathrm{W}$.

TOP OF SMOKE TRAIL

This is probably a fairly definite point physically and represents the place at which incandescence reached the boiling or vaporizing point. Obviously, as this was at a high altitude, the true "boiling point" would be low, but what is here meant is a point at which the stone had fused to a glass of low enough viscosity to be ripped into a vapor or dust by the rush of air. This is a fairly definite point, and observers ought to be able to agree on the position of the top of the trail, whereas they will not agree on the bottom of it, because this is usually settled for each observer by obstructions on his horizon.

Unfortunately, while it would have been easy to sight on the top of the smoke trail with a "transit" at the time of the phenomenon, it would not be easy in most cases to mark the position for future reference, as the open sky rarely has landmarks. A few observers saw the trail through the treetops, or past gable ends of houses, but while these could have been good markers, the observer rarely knew his own position to within a few feet, and this makes a significant error of angle.

Taking account of the various situations of the observers, it appears to us likely that the top of the smoke column actually observed was 
in about latitude $40^{\circ} 45^{\prime} \mathrm{N}$., longitude $79^{\circ} 50^{\prime} \mathrm{W}$., and at a height of about 12 miles.

The horizontal trace of the trajectory passes within 4 miles of downtown Butler, but the meteor was then about 10 miles up in the air, and perhaps 11 miles away in a straight line. The sound of the meteor (the thunder roll) should therefore have begun approximately 1 minute after the flash. All observers estimate a shorter time, but the best of them seem to feel their estimates are underestimates.

\section{WIDTH OF THE SMOKE TRACK}

Several observers near Butler report the track to have been, in their opinion, slightly greater in width than the full moon. As the full moon is very nearly $1 / 2^{\circ}$, we may take their estimates of the width as being $5 / 8^{\circ}$. With the meteor 11 miles distant, this makes the track, after adiabatic expansion, one-eighth of a mile wide, or about 650 feet.

The observer at Nineveh reported the track about half the width of the new moon or less. This would make the track a good deal wider, for Nineveh is far away. Williamson (p. 394) makes it 2,000 feet wide. Heyl's sketch (fig. 19) shows it nearly a mile wide. But these latter observers were viewing the cloud from the south, and the part to which their estimates apply is probably not the same as the part that was most conspicuous at Butler. (See section by Randolph.)

\section{THE SEARCH FOR FURTHER FRAGMENTS}

No other fragments than the two small pieces found by Adam Garing were reported by any of the residents of the area. A few large lumps of ordinary slag were offered us from south of Butler, and were even exhibited in a local store window as possible fragments of the meteorite. A number of scientifically inclined or adventurous helpers undertook to search the region by every available means.

J. M. MeCormick and L. G. Ghering, both of the Preston Laboratories, traveled every back road of the critical areas and made a houseto-house canvass for information. This produced some interesting stories but no fragments. McCormick flew over the area in a small plane, looking for craters or broken trees, and searched the woods on foot wherever he saw anything suspicious from the air, but without result.

George Aderhold, of the Saxonburg Potteries, to whom we are indebted for the recovery of the two fragments from Adam Garing, stationed himself on open hilltops and directed aerial search by two young aviators $(37,38)$. These boys flew over the valleys at so low an altitude that they located most of the groundhog holes, apparently, and almost skimmed the treetops. They reported that the ice storm 
of the previous spring had broken off so many trees and branches of trees, that anything the meteor might have done was indistinguishable. Aderhold, like McCormick, tried to search the area on foot, with equally little result.

The evidence at Garing's farm is that the fragments are comparatively small and fell vertically. If they are all alike, the fragments could do little damage, would not break trees except in the rarest of instances, and would just about bury themselves in the forest floor.

\section{THE RECOVERED FRAGMENTS}

Thus it comes about that from the welter of confused and sometimes conflicting reports the only tangible objects available are two small black pebbles, the larger not 3 inches long. The material in the smoke trail may have weighed tons, and tons of fragments may have reached the earth, but all we have, or are ever likely to have, for detailed examination, are a few ounces now in the United States National Museum. It seems strange that the whole countryside could be rocked from Pittsburgh to Petrolia, a distance of 50 miles, and that startled observers should see the flaming apparition from points 200 miles apart, and yet all that should be recovered be so small a matter. Big noises evidently produce little by way of result.

Small as the fragments are, however, they probably tell us substantially as much as if we had the whole meteor, for it seems reasonable to assume that the rest of the meteor was like the samples.

\section{AUTHORITIES CITED}

(1) Jay Sproul, Nineveh, Pa.

(2) Thomas Monks, Oil City, Pa.

(B) Numerous observers.

(4) George Bottcher, architect, observing from Cooperstown, Pa.

(5) G. E. Sadlon

(6) Kenneth Walborn 3 KDKA broadcasting station, Saxonburg, Pa.

(7) Group of ball players near Kaylor, Pa., C. B. Williams reporting.

(8) U. S. Weather Bureau, Pittsburgh Municipal and County Airport, 10 miles south of Pittsburgh, R. W. Carey reporting.

(9) Farmer's wife.

(10) Adam Garing, Chicora, Pa.

(11) Mrs. J. A. Llewellyn, Butler, Pa.

(12) T. C. Baker, Butler, Pa.; checked by calculation. See page 387.

(13) Mrs. William Clarkin, New Kensington, Pa.

(14) Miss Kate Black, Butler, Pa.

(15) Mrs. F. H. Hayes, Butler, Pa.

(16) Pittsburgh Post-Gazette, June 25, 1938.

(17) Martin Reiber, Butler, Pa.

(18) Butler Eagle, June 25, 1938.

(19) Mrs. Meyers, near Kaylor.

(20) Dr. J. A. Llewellyn.

(21) Dean Bell, Karns City. 
(22) The only explanation so far advanced is the possibility of a mirage lifting the apparent positions considerably above the true one.

(23) S. B. Dengler, Reno, Pa.

(24) Mrs. E. C. Ifft, Franklin, Pa.

(25) Charles McCurdy, Tuscaloosa, Ala., reported the information given.

(26) Harold Miles East Palestine, Ohio, golf course, 2 miles south of Nesley,

(27) Donald Miles\} Ohio.

(28) Frank Kuba, Oakmont, Pa.

(29) Mrs. Frank Kuba, Oakmont, Pa.

(30) Mat Whitlock, Oakmont, Pa.

(81) W. H. Knoch, Saxonburg, Pa.

(32) Charles Walters, near the Stepp Inn, Pennsylvania Route 8, about 7 miles south of Butler, $\mathrm{Pa}$.

(33) Mr. Honzo, KDKA broadcasting station, Saxonburg, Pa.

(34) Carmen Curcio.

(35) Miss Mary Campbell, Butler, Pa.

(36) Harry C. Heyl, North Side Pittsburgh, Pa.

(s7) W. H. Knoch, Saxonburg, Pa.

(38) Dale Rudert, Saxonburg, Pa.

\section{CALCULATIONS OF THE SIZE OF THE METEOR FROM CONSIDERATIONS OF ENERGY}

\section{By JAMES R. RANDOLPH}

Kinetic energy from a meteor is absorbed by the air in two ways: Part of it goes into the production of the sound waves, and part goes into heating the air through which the meteor passes, and at the higher speeds into evaporating the material of which the meteor is composed.

No attempt has been made to compute the energy transformed into sound. But in the case of the Chicora meteorite it has been possible to compute the nonsonic, or heat, energy with what is believed to be a fair degree of accuracy, and from this to compute the weight of that portion of the meteor whose kinetic energy may be assumed as wholly transformed into heat.

This is possible in this case because there is reason to believe that the velocity of approach of the meteorite was small compared to the velocity given it by the earth's attraction, and because its velocity, which in the upper air may have amounted to about 45,000 feet a second, had been reduced to less than 1,000 feet a second by the time the remains of the meteor struck the ground. Thus the kinetic energy per pound is known. And a way is developed for computing the total nonsonic energy from the size of the smoke cloud. This permits an approximate computation of the weight of the meteor.

Observers west of the path of the meteorite describe it as leaving a smoke trail that looked at first like a white pencil mark in the sky, then expanded in about $1 \frac{1}{2}$ seconds to a width that has been computed as approximately 650 feet. After this it expanded and diffused more 
slowly until it disappeared. Since most of these observers were in the vicinity of Butler, the estimate applies primarily to the width at that point.

Observers south of the meteor path, in the northern suburbs of Pittsburgh, describe the meteorite as forming a very much larger cloud than was seen at Butler. Williamson's estimates give it a width of about 2,000 feet, while Heyl's (36) show it more nearly a mile in greatest width. Both these agree in showing a cloud rather thick in its midheight and tapering off above and below.

This discrepancy may be understood by reconstructing the probable reactions of the observers, and what they saw and what they missed. Observers at Butler saw the brilliant meteor flash across the sky. Their eyes followed it into the north and then traveled back along the smoke cloud, which was here about 5 miles away and 9 miles up in the air. Their eyes would then linger on the larger cloud and would fail to see the smaller cloud above it, which soon disappeared. And the large upper cloud would be taken for a simple expansion of an extension of the lower cloud.

Observers to the south, on the other hand, came nearer to seeing the whole thing at once. They could see it all without turning their heads. It was greatly foreshortened to them, so that the bigness of the upper cloud would be more conspicuous. Also the thin-pointed cloud above it would be more noticeable.

Plate 57 is an attempt to reconstruct the meteor trail as it would be seen from the west by an observer at an infinite distance. Heyl's proportions are used, as these have come in the form of a sketch (fig. 19) and hence are possibly more reliable than an estimate of a narrow angle made after the cloud had disappeared.

The cloud thus has two more or less distinct sections. There is the upper section extending from the 12-mile level to the 10-mile, having a length of about 4 miles and an average diameter of 3,500 feet. And there is the lower cloud, tapering down from a maximum of about 650 feet. The path makes an angle of $31^{\circ}$ with the horizontal. The dotted line shows the probable trajectory of the small pieces that fell in the chickenyard at Chicora and suggests that they were detached in this big cloud. As they were not seen coming down, it is probable that by the time they emerged from the cloud their velocity had already fallen to less than a mile a second, which makes this trajectory about right.

Observers south of Chicora describe the sound made by the meteorite as a thunderclap, very prolonged and violent.

Observers at Chicora compare it to an airplane, or to "the wheels of the thunder wagon."

Observers north of Chicora call it a hiss. 
An airplane propeller used for a wind tunnel makes the characteristic airplane sound when at full speed. But this is due to the driving of the propeller tips at a velocity close to that of sound, since the electric motor driving it is silent.

The most conspicuous difference between the thunder sound and an airplane sound is that the latter starts low and rises as the plane draws nearer, since the plane's speed is substantially less than that of sound. But thunder starts with the loudest noise, since it is made by something that is going a great deal faster than sound.

An unstreamlined body traveling at a speed less than that of sound makes a hissing noise.

From these facts we may conclude that when the meteor reached Chicora its speed was approximately that of sound, or about 1,000 feet a second. Its speed when it struck the atmosphere was probably about 45,000 feet a second. Gravity alone would give it 36,900 , to which its velocity of approach must be added vectorially. At this speed its kinetic energy would be:

\section{$1 / 2 M V^{2}=31.4 \times 10^{6}$ foot-pounds per pound.}

Plate 58 shows the way in which the kinetic energy is absorbed by the air. As the meteor's velocity is far above that of sound, the air in front of it is very highly compressed and is heated by the compression to white heat, probably to well over $2,000^{\circ} \mathrm{C}$. Then a sound wave spreads out from it, like the waves from the bow of a boat. And this sound wave may be white hot near the meteor. As before mentioned, this sound wave accounts for part of the energy, which is neglected in the present computation. It also accounts for the thunderclap heard by observers south of Chicora.

Between the sound wave and the meteor the intensely compressed hot air rushes back into the vacuum behind the meteor and forms a turbulent wake. Except for its incandescence, this whole appearance is similar to that observed in a spark photograph of a bullet in flight. ${ }^{2}$

But heat from the air is transferred to the meteor, causing its surface to melt. The molten matter is carried back into the turbulence, where it is atomized to form smoke and its heat given up to the air. An iron meteor loses weight through this melting. But a stony meteor, through at least a part of its course, does not merely melt. It spalls. Pieces of the surface are broken off by rapid expansion and are carried back into the turbulence, where they act as independent small meteors until finally disintegrated and turned into smoke or slowed to the point where further disintegration ceases. The latter is what happened to the two small pieces that were found.

${ }^{2}$ See National Bureau of Standards Scientific Paper No. 508. 
This action is complicated, so that the result we are after can be obtained more simply by applying the box theorem to the process. In this case we put the box around the front part of the turbulence, so that at the front the nonsonic part of the meteor's kinetic energy is going into the box, and at the rear there is coming out a smoke cloud, expanded to atmospheric pressure and completely stopped, but not yet diffused into the surrounding air. As no energy or matter of any consequence goes in or out elsewhere, and as there is no storage, then the energy going into the box, in the form of kinetic energy, must equal the energy coming out, in the form of increased $P V$ energy of the smoke cloud.

$$
\text { Energy }=P V \frac{T_{2}-T_{1}}{T_{2}},
$$

where $P$ is the atmospheric pressure, $V$ the volume of the smoke cloud, $T_{2}$ the absolute temperature of the smoke cloud at this stage, and $T_{1}$ the absolute temperature of the atmosphere.

In this computation the product $P V$ is computed first, and the temperature brought in later as a correction term. The smoke cloud is divided into two parts: The "upper" cloud, extending from the 12-mile level down to the 10 -mile, and having an average diameter, from Heyl's sketch (fig. 19) of 3,500 feet, and the "lower" cloud, extending from there to Chicora. Because it runs through a wide pressure range, the lower cloud is computed as a series of cylinders, while a single computation suffices for the upper cloud.

For both computations the formula, in English units, is:

$$
P V=L D^{2} \frac{\pi}{4} \times 144 P=\frac{144 \pi L}{4} \times D^{2} P .
$$

From top to bottom of the upper cloud the difference in altitude is 2 miles, and the lower cloud is divided into sections of the same length. Hence $L=\frac{2 \times 5,280}{\sin 31^{\circ}}=20,700$ feet.

For the lower cloud the product $D^{2} P$ is computed separately for each section; then these are added and multiplied by the rest of the

\begin{tabular}{|c|c|c|c|c|}
\hline A verage altitude (miles) & $D$ & $D^{2}$ & $P$ & $D^{2} P$ \\
\hline 3 & 350 & 122,500 & 8.16 & $1,000,000$ \\
\hline 5 & 450 & 202,500 & 5.30 & $1,072,000$ \\
\hline 7. & 550 & 302,500 & 3.19 & 966,000 \\
\hline 9 & \multirow[t]{2}{*}{650} & \multirow[t]{2}{*}{422,500} & \multirow[t]{2}{*}{2.03} & 858,000 \\
\hline Total lower cloud. & & & & $3,896,000$ \\
\hline 11 & 3,500 & $12,250,000$ & 1. 22 & $14,950,000$ \\
\hline
\end{tabular}
equation, which has a value of $2,330,000$. 
For the lower cloud $P V=3,896,500 \times 2,330,000=9.3 \times 10^{12}$.

For the upper cloud $P V=14,950,000 \times 2,330,000=34.8 \times 10^{12}$.

Dividing each by $31,400,000$ we get the amount of material whose energy is required to produce each cloud. This is:

For the lower cloud 296,000 pounds $=148$ tons.

For the upper cloud $1,108,000$ pounds $=554$ tons.

We can now apply the temperature correction. Temperatures of the air along the path of the meteor are $-51^{\circ} \mathrm{C}$., or $222^{\circ}$ abs., for the upper cloud, and about $230^{\circ}$ abs. on the average for the lower. The temperature of the cloud after expansion is roughly estimated at $900^{\circ}$ abs. But the error is much greater than the difference between $222^{\circ}$ and $230^{\circ}$. Hence $230^{\circ}$ is used for both, and the temperature correction factor becomes

$$
\frac{900-230}{900}=0.74
$$

Hence the weights become, for the lower cloud:

$$
148 \times 0.74=109 \text { tons. }
$$

For the upper cloud:

$$
554 \times 0.74=\frac{410 \text { tons. }}{519 \text { tons. }}
$$

The shape of the cloud can also give us some idea as to the structure of the meteor. The lower cloud appears to have been formed by a single solid, about as compact as the fragments recovered, melting and spalling at a fairly uniform rate. And that high extension of the upper cloud, which has not been computed, may be of the same nature.

But the shape of the upper cloud, and its "jagged-edged appearance" as described by Heyl, suggest that it is of a different nature. Something seems to have happened at the 12-mile level, which can best be described as a sudden crushing of a loose outer structure surrounding the more compact central core. This outer structure weighed 410 tons to 109 for the inner core, which probably gives the proportionate size of the two, even if we could add the mass required to produce the sonic energy.

What was this loose outer structure?

At the Bureau of Standards is a cross section of a pot of optical glass that has been allowed to cool rapidly. The whole outer portion has cracked up, leaving only a few large lumps at the center. And a large stony meteor, passing near the sun, would probably be similarly cracked. It would have at least a slow rotation. The side toward the sun would be heated, and the side away from it cooled, through tem- 
perature ranges comparable to those found on the moon or Mercury. And because the material is a poor conductor of heat, this alternate heating and cooling would set up temperature stresses and form cracks extending deeply into the mass, even as they do into a pot of optical glass.

If this big meteorite had come straight down instead of at this long slant, it would have reached the earth with a lot of its structure still intact and a lot of its energy still in it. And if it had landed on Pittsburgh there would have been few survivors. Its kinetic energy of $31,400,000$ foot-pounds per pound is more than 20 times as great as the explosive energy of TNT.

At least its capacity for destruction would have compared favorably with that of the shipload of TNT that blew up in Halifax Harbor in 1917. And such a catastrophe, or even a very much larger one, can happen at any time, with no more warning than the observers of the Chicora meteorite had. But fortunately the energy of this meteorite had all been absorbed by the air before it reached the ground.

\section{MINERALOGICAL DESCRIPTION OF THE METEORITE}

\section{By E. P. HENDERSON}

Only two specimens of the Chicora meteorite have so far been recovered, the larger one weighing 242 grams and the smaller 61 grams; both are deposited in the United States National Museum (No. 1326). The latitude of the place of discovery is $40^{\circ} 56^{\prime} \mathrm{N}$. and the longitude $79^{\circ} 44^{\prime} \mathrm{W}$. Both individuals are covered with a thin film of black fused crust, and neither shows any evidence of being orientated through much of its flight. Shallow and irregular depressions (thumb marks) are noticeable on each, but no unusual physical features are present.

When the crust was removed a fine-grained texture was found exhibiting a rather uniform gray color. All the component minerals are so small that none could be recognized by the unaided eye, unless it be an occasional inclusion of bronze-colored troilite. On the freshly broken surface no conspicuous evidence was observed of the chondritic nature of this meteorite, and not until a thin section was prepared could positive proof of this be given. From the smooth surface, made by cutting away a portion for the thin section, a dappledgray pattern is noticeable. The darker gray material is in rounded, as well as slightly elongated, chondrules or portions of chondrules, each being separated by a thin zone of lighter gray material. The texture is just firm enough to make it slightly difficult to break apart by the use of a steel tool. 


\section{PREPARATION OF SAMPLE FOR CHEMICAL ANALYSIS}

Material for study was taken from the smaller specimen. The fused crust was removed by using a steel dental pick, and by this same instrument the central portion was found to be rather easily broken apart. The material selected was carefully examined to free it from the crust and then partly crushed and sized by screening through a 140-mesh sieve, and divided it into two portions, one of which was less than 140 mesh and the other coarser, but still less than 80 mesh. This step was taken in the hope that it would be possible to separate the metallic portion from the silicates by using an electromagnetic separator. There was enough iron dust or magnetic particles associated with both fractions to prohibit satisfactory separation by the electromagnet.

A small portion of the magnetic material was removed from one of the samples and unfortunately lost. This made it dangerous to combine the samples again; hence each portion, the coarse and the fine, was analyzed as a separate sample. The author does not recommend this procedure for stony meteorites, and if there had been a greater quantity of material available from which to select a new sample these two portions would have been discarded and a new one prepared.

The samples taken for analyses were digested in mixed nitric and hydrochloric acids for 12 hours. This treatment took into solution all the metallic minerals, except a grain or so of chromite, and completely decomposed the olivine. The silica from the olivine along with the insoluble material was filtered off and the separated silica subsequently removed from the insoluble residue by digestion in sodium-carbonate solution. Very little of the silica separated from the olivine was present in the acid filtrate; apparently the silica is largely separated out if the acid stands in contact with the olivine for some time. After the removal of the silica the insoluble portion was carefully ignited at low temperature necessary to burn off filter paper and preserved in order that it might be separately analyzed chemically and mineralogically.

Table 2 gives the results of the analysis on both the fine-grained portion and the coarse.

\section{OLIVINE}

The composition of the olivine was determined from the analysis of the soluble material. It had to be assumed that the silica, soluble in the sodium carbonate, together with the small portion recovered in the acid filtrates was entirely derived from the olivine. Several side experiments, of a qualitative nature, were conducted, and it was found that olivine is very easily attacked by acids, even weak organic ones such as tartaric. The magnesium in the soluble portion was also 


\section{CHICORA METEORITE-PRESTON, HENDERSON, RANDOLPH 409}

TABLE 2.-Analysis of the acid-soluble portion of the Chicora meteorite

E. P. HENDERSON, analyst

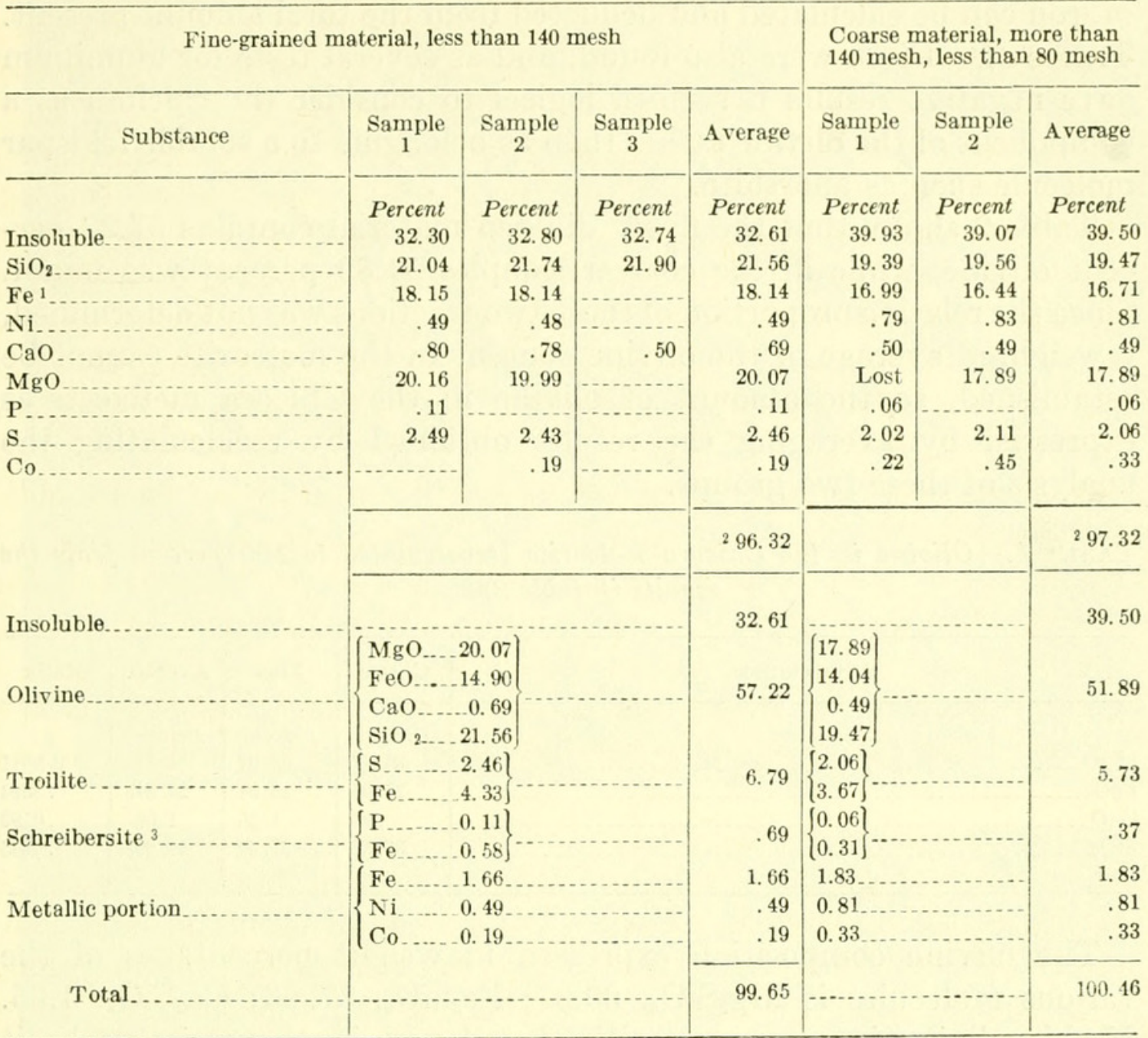

${ }^{1}$ Includes acid sol. FeO.

${ }^{2}$ Low summation due to calculating all $\mathrm{FeO}$ as Fe.

${ }_{3}^{3}$ Phosphorus could be present as merrillite, but neither schreibersite nor merrillite was recognized.

TABLE 3.-Analysis of the insoluble material in the Chicora meteorite

E. P. HeNDERSon, analyst

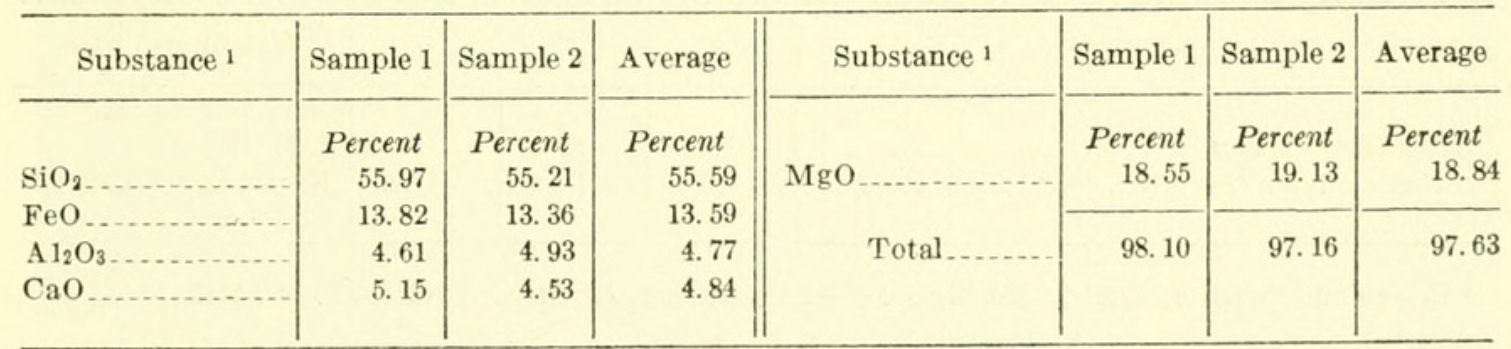

$1 \mathrm{Cr}$ and $\mathrm{Ti}$ were found present but not determined. Na was not determined, but it must be present in the feldspar molecule. 
considered as being entirely derived from the olivine. Hence, if we know the magnesium and the silica content, the necessary quantity of iron can be calculated and deducted from the total amount present. Traces of calcium were also found, and as several tests for aluminum gave negative results it seemed logical to consider the calcium as a component of the olivine rather than as belonging to a soluble feldspar molecule such as anorthite.

Table 2 shows that the finely divided material contains 57.22 percent olivine, while in the coarser samples 51.89 percent was found. Since the relative proportion of these two fractions was not determined, a weighted average of the olivine content in the meteorite cannot be established, so the amount of olivine in the Chicora meteorite is expressed by averaging the results obtained by recalculating the analysis of these two groups.

TABLE 4.-Olivine in the Chicora meteorite (recalculated to 100 percent from the results in table 2)

\begin{tabular}{|c|c|c|c|c|}
\hline Substance & Coarse & Fine & A verage & Ratio \\
\hline $\mathrm{MgO}_{\text {. }}$ & $\begin{array}{r}\text { Percent } \\
34.47\end{array}$ & $\begin{array}{r}\text { Percent } \\
35.07\end{array}$ & $\begin{array}{c}\text { Percent } \\
34.72\end{array}$ & 0.8611 \\
\hline $\mathrm{FeO}$ & 27.05 & 26.04 & 26. 545 & .3694 \\
\hline $\mathrm{CaO}_{2}$ & .96 & 1. 20 & 1.08 & .0192 \\
\hline $\mathrm{SiO}_{2} \ldots . . .$. & 37.52 & 37.69 & 37.605 & .6235 \\
\hline
\end{tabular}

The olivine composition expressed in weight percentages of the various molecules is $\mathrm{Mg}_{2} \mathrm{SiO}_{4}, 60.67 ; \mathrm{Fe}_{2} \mathrm{SiO}_{4}, 37.63 ; \mathrm{Ca}_{2} \mathrm{SiO}_{4}, 1.65$. If this olivine is compared with that found in terrestrial rocks it will seem to be unusually high in iron. It is well above the average iron content for olivines in pallasites, although the olivines in stony meteorites sometimes run as high in iron as this one.

The indices of refraction determined by the immersion method gave values agreeing very well with the composition of this olivine:

\begin{tabular}{c|c|c|c|l}
\hline \multicolumn{1}{c|}{ Specimen } & \multicolumn{1}{c|}{$\alpha$} & \multicolumn{1}{c|}{$\beta$} & \multicolumn{1}{c|}{$\gamma$} & \multicolumn{1}{|c}{ Determined by- } \\
\hline & & & & \\
Olivine from Chicora & 1.695 & 1.712 & 1.735 & J. J. Glass. \\
Synthetic olivine $\left(\mathrm{Mg}_{2} \mathrm{SiO}_{4}, 60 ; \mathrm{Fe}_{2} \mathrm{SiO}_{4}, 40\right) \ldots . . .-$ & 1.705 & 1.730 & 1.748 & Bowen and Schairer. \\
\hline
\end{tabular}

${ }^{1}$ Bowen and Schairer, The system $\mathrm{MgO}-\mathrm{FeO}-\mathrm{SiO}_{2}$. Amer. Journ. Sci., vol. 29, p. 197, 1935.

The olivine in this meteorite has two different modes of occurrence:

(a) There are fragments of a banded chondrulitic olivine structure (see pl. 59, A) but no complete chondrules. The banded or barred 


\section{$2 \mathrm{BHL}$ Biodiversity Heritage Library}

Preston, F. W., Henderson, E P, and Randolph, James R. 1941. "The Chicora (Butler County, Pa.) meteorite." Proceedings of the United States National Museum 90(3111), 387-416. https://doi.org/10.5479/si.00963801.90-3111.387.

View This Item Online: https://www.biodiversitylibrary.org/item/32375

DOI: https://doi.org/10.5479/si.00963801.90-3111.387

Permalink: https://www.biodiversitylibrary.org/partpdf/14465

\section{Holding Institution}

Smithsonian Libraries

\section{Sponsored by}

Smithsonian

\section{Copyright \& Reuse}

Copyright Status: NOT_IN_COPYRIGHT

Rights: https://www.biodiversitylibrary.org/permissions/

This document was created from content at the Biodiversity Heritage Library, the world's largest open access digital library for biodiversity literature and archives. Visit BHL at https://www.biodiversitylibrary.org. 